\title{
ALUMINA COM ADIÇÕES DE NIÓBIA, SÍLICA E MAGNÉSIA PARA PROTEÇÃO BALÍSTICA*
}

\section{Resumo}

\author{
Alaelson Vieira Gomes ${ }^{1}$ \\ Carlos Frederico de Matos Chagas ${ }^{2}$ \\ Willian Trindade ${ }^{3}$ \\ Edio Pereira Lima Júnior ${ }^{4}$ \\ Paulo Roberto Rodrigues de Jesus ${ }^{5}$ \\ Lucio Fabio Cassiano Nascimento ${ }^{6}$ \\ Jheison Lopes dos Santos ${ }^{7}$ \\ Aldélio Bueno Caldeira ${ }^{8}$ \\ Sergio Neves Monteiro ${ }^{9}$ \\ Luis Henrique Leme Louro ${ }^{10}$
}

Amostras de alumina APC-2011 SG com nióbia, sílica e magnésia foram sinterizadas a $1400{ }^{\circ} \mathrm{C} / 3 \mathrm{~h}$, a fim de serem avaliadas suas propriedades balísticas. A adição de nióbia foi de $6 \%$ e $8 \%$ em peso; sílica foi de $0 \%$ e 0,8\% em peso; e magnésia no teor de $0 \%$ e $0,15 \%$ em peso. As amostras sinterizadas foram caracterizadas medindo-se dureza, densificação e velocidade após o impacto.

Os ensaios balísticos foram efetuados colando discos cerâmicos em chapas de aço e então submetendo o alvo a impacto usando projetil $7,62 \mathrm{~mm}$ de um fuzil com uma distância de tiro de 5m. A energia absorvida pela fragmentação dos discos cerâmicos foi estimada pela velocidade residual.

As superfícies de fratura das amostras foram observadas por microscopia eletrônica de varredura. Os resultados foram analisados.

Verificou-se que a adição de quantidades elevadas de nióbia à alumina com presença menos significativa de sílica e magnésia pode incrementar a presença de fase vítrea nos contornos de grãos da alumina, com efeito nas propriedades do material para uso em proteção balística.

Palavras-chave:Blindagem; Alumina; Nióbia; Sílica; Magnésia

\section{ALUMINA WITH ADDITION OF NIOBIA, SILICA AND MAGNESIA FOR BALLISTIC PROTECTION}

\section{Abstract}

Samples of alumina APC-2011 SG with nióbia, silica and magnesia were sintered at $1400{ }^{\circ} \mathrm{C} / 3 \mathrm{~h}$, in order to evaluate their ballistic properties. The addition of niobia was $6 \%$ and $8 \%$ by weight; silica was $0 \%$ and $0.8 \%$ by weight; and magnesia at $0 \%$ and $0.15 \%$ by weight. The sintered samples were characterized by measuring hardness, densification and velocity after impact.

Ballistic tests were performed by gluing ceramic discs to steel plates and then subjecting the target to impact using a projectile $7.62 \mathrm{~mm}$ from a rifle with a throw distance of $5 \mathrm{~m}$. The energy absorbed by the ceramic discs was estimated by the residual velocity.

The fracture surfaces of the samples were observed by scanning electron microscopy. The results were analyzed.

It was verified that the addition of high amounts of nióbia to the alumina with less significant presence of silica and magnesia can increase the presence of vitreous phase in the grain contours of the alumina, with effect in the properties of the material for use in ballistic protection.

Keywords: Armor; Alumina; Niobia; Silica; Magnesia Ceramic 
1 Engenharia Metalúrgica, Doutorado em Ciência dos Materiais, Professor, Seção de Engenharia Mecânica e de Materiais, Instituto Militar de Engenharia (IME), Rio de Janeiro, RJ e Brasil.

2 Engenharia Mecânica e de Armamento, Doutorado em Ciência dos Materiais, Pesquisador, Divisão de Sistemas, Centro Tecnológico do Exército, Rio de Janeiro, RJ, Brasil

3 Engenharia Química, Doutorado em Ciência dos Materiais, Professor, Curso de Licenciatura em Computação, Universidade do Estado do Amazonas (UEA), Manaus, AM e Brasil.

4 Engenharia Mecânica e de Armamento, Mestrado em Engenharia Mecânica, Aluno de Doutorado, Seção de Engenharia Mecânica e de Materiais, Instituto Militar de Engenharia (IME), Rio de Janeiro, RJ e Brasil

5 Engenharia Metalúrgica, Mestrado em Ciência dos Materiais, Professor, Seção de Engenharia Mecânica e de Materiais, Instituto Militar de Engenharia (IME), Rio de Janeiro, RJ e Brasil.

6 Engenharia Metalúrgica, Doutorado em Ciência dos Materiais, Professor, Seção de Engenharia Mecânica e de Materiais, Instituto Militar de Engenharia (IME), Rio de Janeiro, RJ e Brasil.

7 Licenciado em Física, Doutorado em Ciência dos Materiais (IME), Pós-doutorando, Seção de Engenharia Mecânica e de Materiais, Instituto Militar de Engenharia (IME), Rio de Janeiro, RJ e Brasil

8 Engenharia Mecânica, Doutorado em Engenharia Mecânica, Professor, Seção de Engenharia Mecânica e de Materiais, Instituto Militar de Engenharia (IME), Rio de Janeiro, RJ e Brasil

9 Engenharia Metalúrgica, Ph.D. em Ciência dos Materiais, Professor, Seção de Engenharia Mecânica e de Materiais, Instituto Militar de Engenharia (IME), Rio de Janeiro, RJ, Brasil.

10 Engenharia Metalúrgica, Doutorado em Ciência dos Materiais, Professor, Seção de Engenharia Mecânica e de Materiais, Instituto Militar de Engenharia (IME), Rio de Janeiro, RJ e Brasil. 


\section{INTRODUÇÃO}

Cerâmicos [1], como a alumina, são pesquisados há várias décadas para aplicação em blindagem balística de viaturas militares, pela elevada dureza e baixo peso, promovendo a fragmentação de projetis durante o impacto, com baixa densidade superficial da blindagem.

ACCHAR [2] verificou que a alumina contendo $4 \%$ de nióbia $\left(\mathrm{Nb}_{2} \mathrm{O}_{5}\right), 0,8 \%$ de sílica $\left(\mathrm{SiO}_{2}\right)$ e $1,15 \%$ de magnésia $(\mathrm{MgO})$ sinterizada a $1400{ }^{\circ} \mathrm{C} / 3 \mathrm{~h}$ apresenta um valor de resistência mecânica da mesma ordem de grandeza de uma alumina padrão com $0,15 \% \mathrm{MgO}$ sinterizada a $1600^{\circ} \mathrm{C} / 1 \mathrm{~h}$. Este resultado indica a viabilidade de estudos da adição de nióbia, sílica e magnésia à alumina para emprego em blindagem, com redução da temperatura de sinterização e dos custos de equipamentos de fabricação.

A sílica [2] reage com a alumina, formando mulita $\left(3 \mathrm{Al}_{2} \mathrm{O}_{3}\right.$. $\left.2 \mathrm{SiO}_{2}\right)$, que tem efeito inibidor de crescimento de grão. A presença de nióbia na alumina sinterizada forma uma 2 a fase nos contornos de grãos da alumina, o niobato de alumina $\left(\mathrm{AlNbO}_{4}\right)$, com aumento da densificação e dureza.

$\mathrm{Na}$ presença de $\mathrm{SiO}_{2}$ e $\mathrm{MgO}$, a nióbia reage com a magnésia formando a magnocolumbita $\left(\mathrm{MgNb}_{2} \mathrm{O}_{6}\right)$. Verificou-se [2] que um aumento do teor de $\mathrm{Nb}_{2} \mathrm{O}_{5}$ de $4 \%$ para $6 \%$ não altera a quantidade de $\mathrm{MgNb}_{2} \mathrm{O}_{6}$, alterando somente a de $\mathrm{AlNbO}_{4}$.

Em outros trabalhos [3, 4, 5], verificou-se que a adição isolada de $4 \%$ de nióbia favorece o uso do material em aplicações balísticas, o que indica ser interessante 0 estudo da adição de teores mais elevados de nióbia à alumina, mantendo baixos os níveis de sílica e magnésia.

Uma das formas de sinterização dos materiais cerâmicos é em presença de fase líquida[6], que envolve três componentes (sólido, líquido e poros). Na temperatura de sinterização, mais de $80 \%$ de material está no estado sólido. Neste caso, é de se esperar que as adições concentrem-se nos contornos de grãos da alumina, tendendo a tornar as superfícies dos grãos arredondadas pelo preenchimento dos defeitos superficiais dos grãos pelas 2 as fases formadas a partir das adições.

A ação dos materiais cerâmicos em blindagem conjugada é efetiva, porque o impacto do projetil com a face cerâmica cria ondas de choque compressivas com altíssimas pressões (da ordem de $30 \mathrm{GPa}$ a $900 \mathrm{~m} / \mathrm{s}$ ), que atravessam o projetil e o cerâmico nas suas respectivas velocidades sônicas, com interação no interior do projetil, ocasionando sua fragmentação. Além disso, quando a ponta do projetil atinge o alvo, uma região muito pequena é submetida a alta compressão, o que provoca o aparecimento de um cone de fraturas $[7,8]$.

Um fator que influencia a perda de energia cinética do projetil ao atravessar um material cerâmico é a usinagem da ponta do projetil pelas partículas produzidas pela fragmentação do material cerâmico, melhorando a eficiência da blindagem. Por conseguinte, é preciso que a face cerâmica tenha uma elevada dureza[7, 8].

A porosidade, quando excessiva, prejudica o desempenho da blindagem, pela queda da dureza e da densificação, porém sua presença residual pode favorecer a proteção balística, por serem pontos de aquecimento localizado[9], onde parte da energia do projétil pode ser convertida em energia térmica. Contudo, é importante um compromisso entre absorção de energia e dureza, pela importância desta para a quebra da ponta do projétil. 


\section{MATERIAIS E MÉTODOS}

Estudou-se as composições cerâmicas à base de uma alumina nacional, APC 2011 SG, da ALCOA, com adições de nióbia, sílica e magnésia, sinterizadas ao ar em um forno NETZSCH com patamar de $1400^{\circ} \mathrm{C}$ por 3h. A Tabela 1 apresenta as composições investigadas.

Tabela 1: Composições investigadas

\begin{tabular}{|c|c|c|c|}
\hline $\begin{array}{c}\mathrm{Al}_{2} \mathrm{O}_{3} \\
\%\end{array}$ & $\begin{array}{c}\mathrm{Nb}_{2} \mathrm{O}_{5} \\
\%\end{array}$ & $\begin{array}{c}\mathrm{SiO}_{2} \\
\%\end{array}$ & $\begin{array}{c}\mathrm{MgO} \\
\%\end{array}$ \\
\hline 93,05 & 6 & 0,8 & 0,15 \\
\hline 92,25 & 8 & 0,8 & 0,15 \\
\hline 94,00 & 6 & & \\
\hline 93,20 & 6 & 0,8 & \\
\hline 92,00 & 8 & & \\
\hline 91,20 & 8 & 0,8 & \\
\hline
\end{tabular}

Os pós cerâmicos no percentual da Tabela 1 foram misturados e moídos em meio aquoso em um Moinho de Bolas CHIAROTTI MAUÁ modelo 18300, por 8 horas. Depois foram levados a uma Estufa ELKA para secagem a $70^{\circ} \mathrm{C}$. Os pós secos foram desaglomerados manualmente utilizando uma espátula, e peneirados em uma peneira vibratória de 70 mesh colocada em um Agitador de Peneiras marca +GF+ tipo PBA. O material que passou nesta peneira foi armazenado na estufa para evitar a reabsorção de umidade, indesejável no processamento. Em cada composição há a presença de $1,5 \%$ de ligantes sobre a massa total, sendo $0,75 \%$ de polietilenoglicol e $0,75 \%$ de álcool polivinílico (PVA) dissolvido em água a $70^{\circ} \mathrm{C}$ aquecida em uma Placa Quente FISATOM modelo 753A. Como os ligantes são evaporados antes da sinterização em um Forno marca HOSKINS, não foram computados para fins de composição dos pós. Estes teores de polietilenoglicol e PVA são resultados empíricos das atividades do Laboratório de Materiais Cerâmicos do IME.

Os pós obtidos foram prensados a $60 \mathrm{MPa}$ como corpos verdes na Máquina Universal de Ensaios de Tração e Compressão marca INSTRON modelo 1116 - 25 Ton, utilizando matrizes metálicas. Foram prensados discos com diâmetro de $57 \mathrm{~mm}$ e altura de $11 \mathrm{~mm}$, para medida de densidade e avaliação balística.

Foram prensadas barras delgadas de dimensões $60 \times 10 \times 6 \mathrm{~mm}^{3}$, para avaliação da microdureza Vickers (HV) com penetrador de diamante no Microdurômetro BUEHLER modelo 2003 e da microestrutura em uma superfície de fratura estática usando microscopia eletrônica de varrredura.

A avaliação da densidade das cerâmicas sinterizadas foi feita de acordo com a norma NBR 6220 [10].

\subsection{Preparação dos alvos}

Os alvos foram constituídos, a partir da superfície de impacto, por uma placa quadrada de aço $1020 \mathrm{com} 10 \mathrm{~cm}$ de lado e $2 \mathrm{~mm}$ de espessura; a placa cerâmica com $57 \mathrm{~mm}$ de diâmetro e duas placas de aço, idênticas à frontal, coladas na parte posterior do cerâmico, como mostrado esquematicamente na Figura 1. 


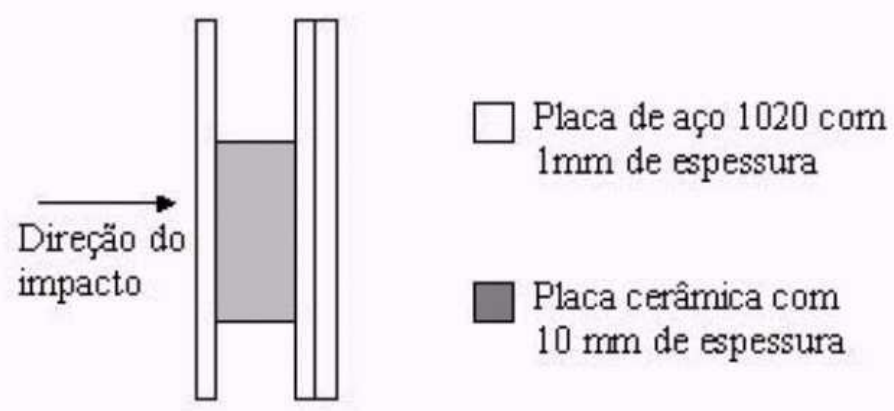

Figura 1 : Alvo para avaliação do material cerâmico

\subsection{Realização dos ensaios balísticos}

Os ensaios balísticos foram conduzidos no Campo de Provas da Marambaia com provete $7,62 \mathrm{~mm}$. Foram realizadas medições das velocidades do projetil antes e após o impacto nos alvos previamente preparados.

A distância de tiro foi de 5 metros para todas as composições cerâmicas.

A partir da velocidade inicial foi calculada a energia cinética do projetil, e quantificada a perda de energia deste ao atravessar a blindagem. Considerou-se que a massa de fragmentos do projétil que atravessou o alvo é igual à massa do projétil antes do impacto balístico.

Uma barreira ótica de detecção foi colocada após o alvo a fim de medir a velocidade residual do projetil após o impacto balístico, permitindo determinar a energia absorvida pelo cerâmico

\section{RESULTADOS E DISCUSSÃO}

\subsection{Microestruturas das composições}

As Figuras 2 a 7 mostram as microestruturas das composições da Tabela 1, obtidas por microscopia eletrônica de varredura. A Figura 7 mostra a microestrutura de uma composição na qual a presença de fase vítrea nos contornos de grãos foi mais intensa, com visível arredondamento dos grãos.

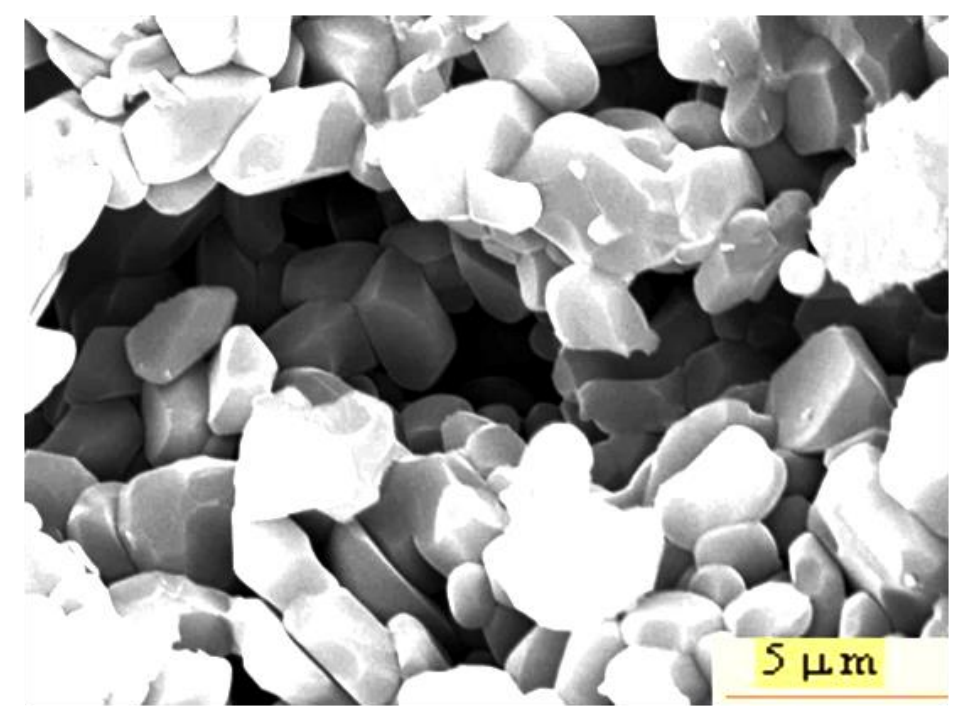

Figura 2: Composição com 6\% Nb2O5, 0\% SiO2 e 0\% MgO 

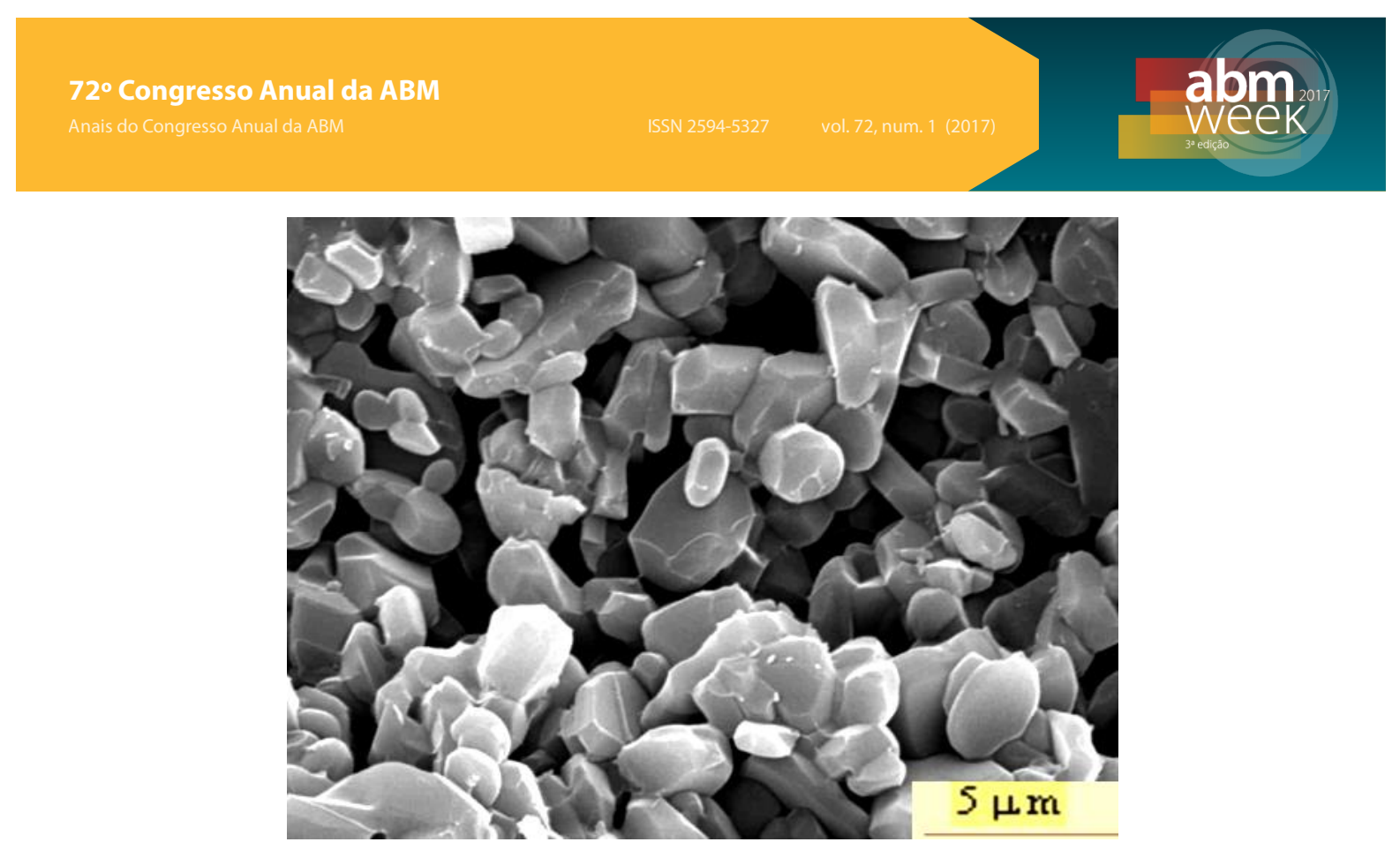

Figura 3: Composição com 6\% Nb2O5, 0,8\% SiO2 e 0\% MgO

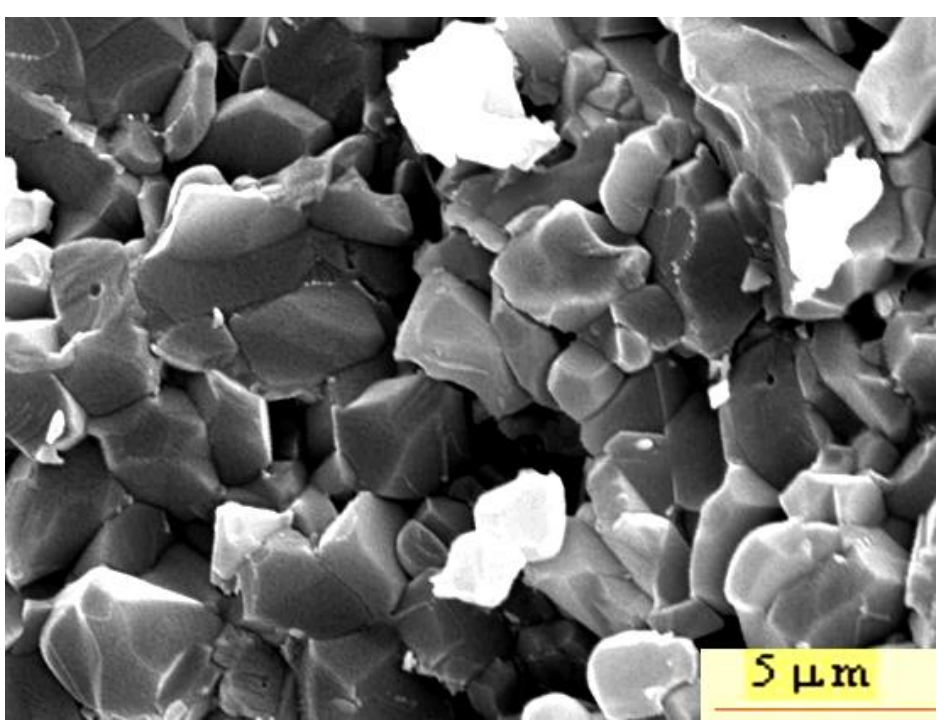

Figura 4: Composição com 6\% Nb2O5, 0,8\% SiO2 e 0,15\% MgO

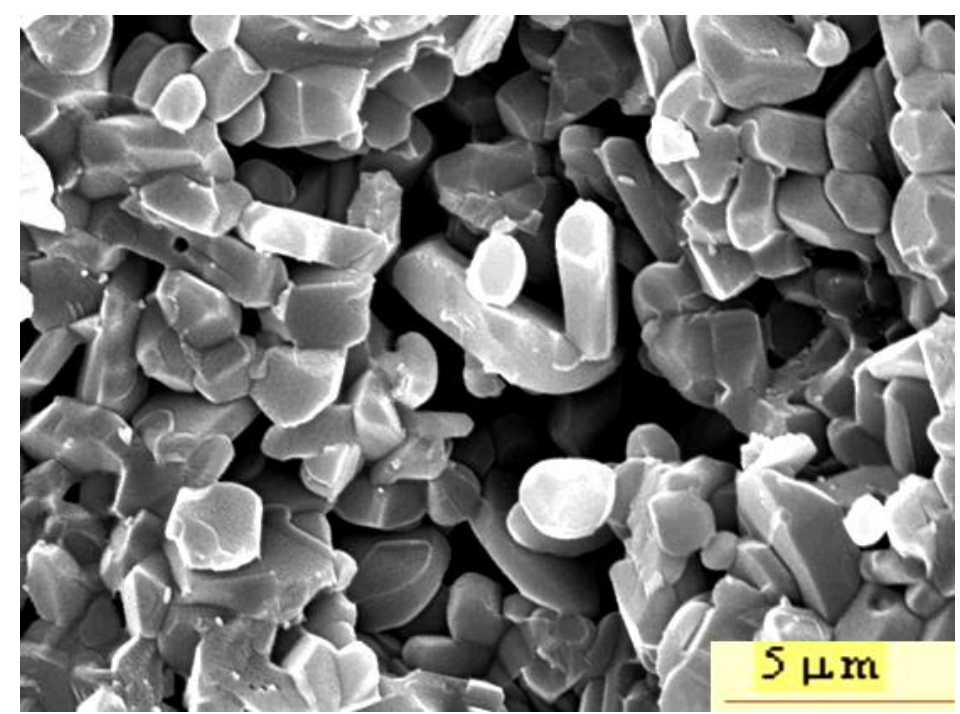

Figura 5: Composição com 8\% Nb2O5, 0\% SiO2 e 0\% MgO 

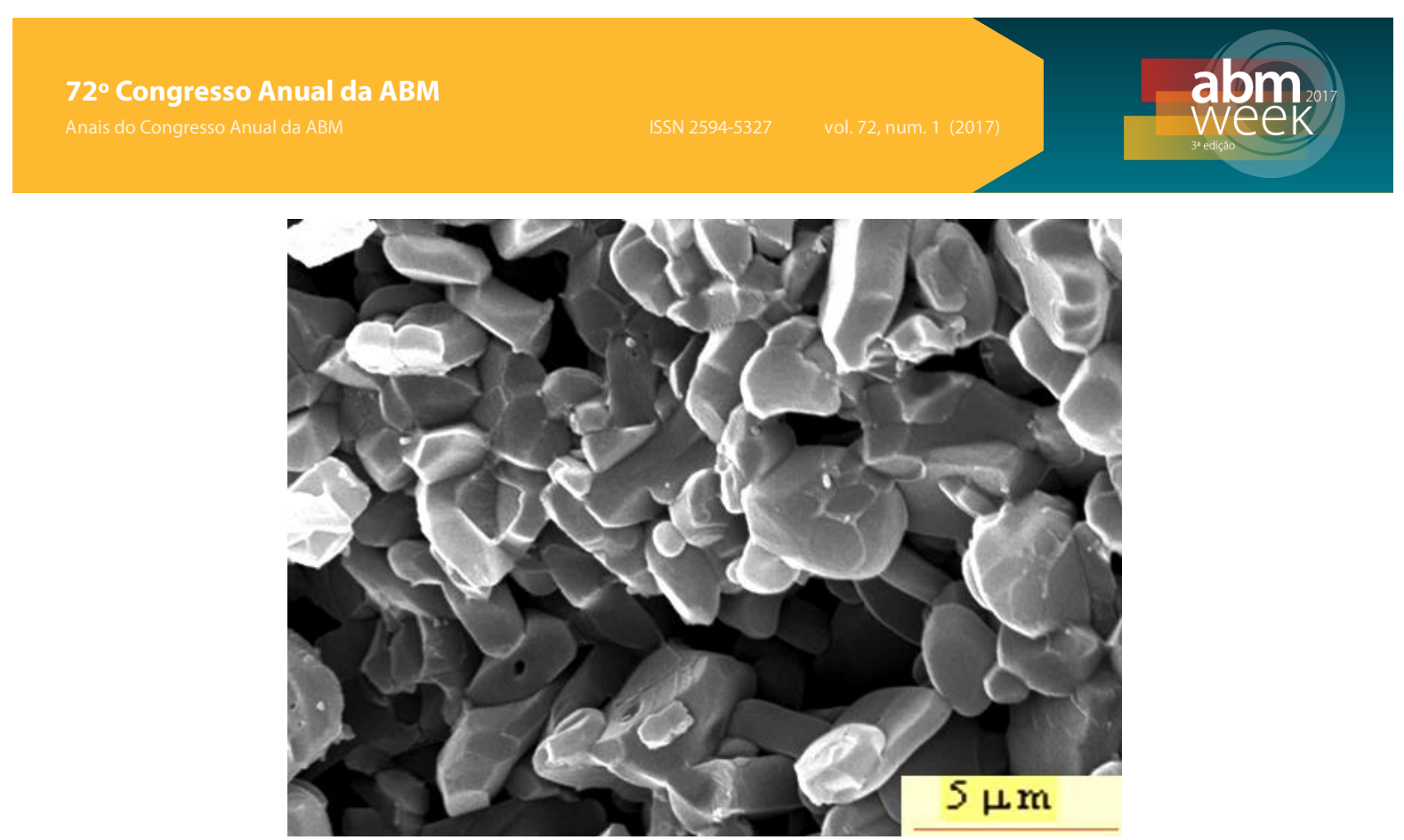

Figura 6: Composição com 8\% Nb2O5, 0,8\% SiO2 e 0\% MgO

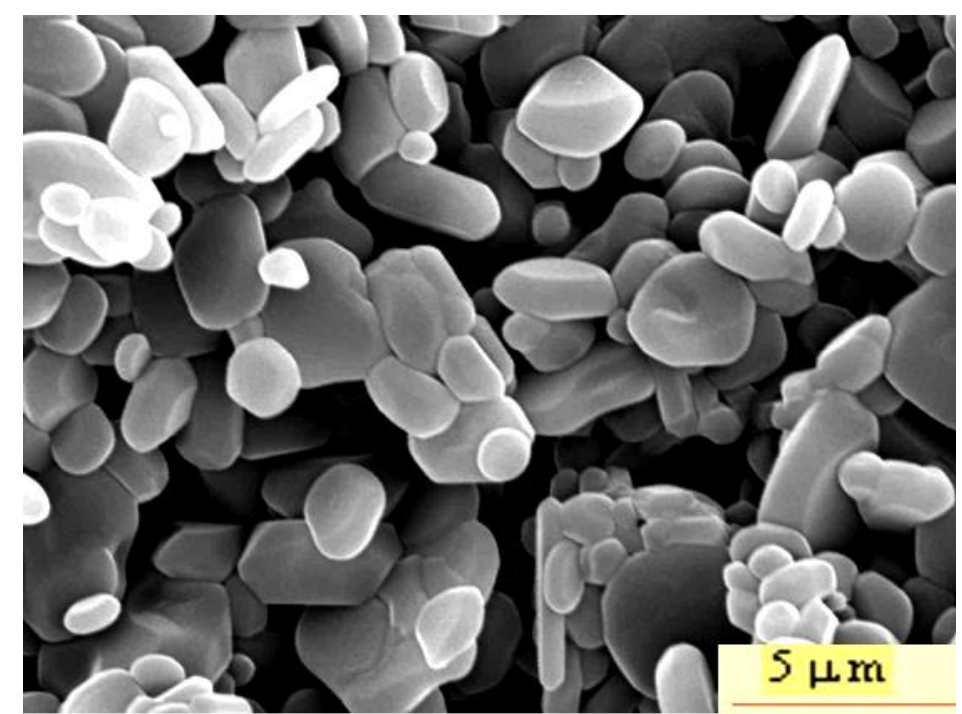

Figura 7: Composição com 8\% Nb2O5, 0,8\% SiO2 e 0,15\% MgO

\subsection{Propriedades medidas nas composições investigadas}

A Tabela 2 apresenta os valores medidos para cada composição da Tabela 1 de microdureza Vickers, densificação e absorção de energia pelo cerâmico, de acordo com os métodos descritos anteriormente.

Tabela 2 : Microdureza Vickers, densificação e absorção de energia pelo cerâmico nas composições

\begin{tabular}{|c|c|c|l|c|c|}
\hline $\begin{array}{c}\text { Nióbia } \\
(\%)\end{array}$ & $\begin{array}{c}\text { Sílica } \\
(\%)\end{array}$ & $\begin{array}{c}\text { Magnésia } \\
(\%)\end{array}$ & $\begin{array}{c}\text { Microdureza } \\
\text { Vickers }\end{array}$ & $\begin{array}{c}\text { Densificação } \\
(\%)\end{array}$ & $\begin{array}{c}\text { Absorção de energia } \\
(\%)\end{array}$ \\
\hline 6 & 0,8 & 0,15 & $1082 \pm 72$ & $86,8 \pm 4,8$ & 83,6 \\
\hline 8 & 0,8 & 0,15 & $947 \pm 79$ & $89,8 \pm 0,3$ & 90,7 \\
\hline 6 & - & - & $966 \pm 59$ & $87,7 \pm 0,4$ & 85,2 \\
\hline 6 & 0,8 & - & $888 \pm 138$ & $80,5 \pm 1,9$ & 91,2 \\
\hline 8 & - & - & $1307 \pm 72$ & $91,2 \pm 0,2$ & 81,9 \\
\hline 8 & 0,8 & - & $761 \pm 77$ & $81,1 \pm 0,8$ & 91,5 \\
\hline
\end{tabular}




\subsection{Microdureza Vickers}

Verifica-se na Tabela 2 que a adição de nióbia isoladamente no teor de $8 \%$ foi a composição de maior dureza, provavelmente pela formação de $\mathrm{AlNbO}_{4}$ nos contornos de grãos da alumina. Observa-se uma queda na dureza quando é adicionado $0,8 \%$ de sílica neste percentual de nióbia, provavelmente pela formação de mulita. Contudo, a adição também de $0,15 \%$ de $\mathrm{MgO}$ eleva sua dureza, porém sem atingir os níveis da adição isolada de nióbia, provavelmente por efeito da formação da fase vítrea nos contornos de grãos, como pode-se verificar na Figura 7. Para $6 \%$ de nióbia, a adição de $0,8 \%$ de sílica e de $0,15 \%$ de magnésia proporciona a maior dureza para este teor de nióbia, provavelmente pelas fases presentes nos contornos de grãos, pela diferença de microestrutura entre as Figuras 4 e 7.

\subsection{Densificação}

As medidas de densificação das composições pela Norma ABNT NBR 6220 [10] são mostradas na Tabela 2. A densificação mostrou-se coerente com a dureza. A adição de nióbia isoladamente no teor de $8 \%$ foi a que proporcionou maior densificação, pela presença de $\mathrm{AINbO}_{4}$ nos contornos de grãos da alumina. Há queda na dureza quando é adicionado $0,8 \%$ de sílica pela formação de mulita. Adicionando-se também $0,15 \%$ de $\mathrm{MgO}$, a densificação aumenta.

Os resultados indicam que a fase vítrea na composição de $8 \%$ de nióbia, $0,8 \%$ de sílica e $0,15 \%$ de magnésia mostrada na Figura 7 favorece a densificação pela molhabilidade dos grãos, tem uma dureza elevada, e é preferencial para formação no lugar da mulita, que se forma quando há presença de apenas alumina, nióbia e sílica.

\subsection{Absorção de Energia Cinética pelo Cerâmico}

A Tabela 2 apresenta os valores de absorção de energia cinética do projétil no impacto pelo material cerâmico, considerando-se que a fragmentação do projétil forme um sistema de partículas com a mesma massa do projétil antes do impacto, e que possa ser desprezado o efeito das placas finas de aço baixo carbono sobre essa absorção de energia.

Os resultados do impacto balístico mostram que para os percentuais de 6 e $8 \%$ de nióbia, há um aumento significativo na absorção de energia pelo material cerâmico, se for adicionado $0,8 \%$ de sílica, provavelmente pela interação das ondas de choque no cerâmico com a mulita presente, apesar das menores dureza e densificação observadas anteriormente para alumina apenas com nióbia e sílica.

Adicionando-se $0,15 \%$ de $\mathrm{MgO}$ para a composição com $8 \%$ de nióbia e 0,8\% de sílica, há uma manutenção da absorção de energia pelo cerâmico, provavelmente pela atuação da fase vítrea nos contornos de grãos dessa última composição. Como para $6 \%$ de nióbia, a adição de $0,15 \%$ de $\mathrm{MgO}$ na presença de $0,8 \%$ de sílica não mostra uma presença tão intensa de fase vítrea, este efeito do $\mathrm{MgO}$ é menos significativo. Para esta composição houve a maior dureza, contudo não teve a maior absorção de energia ao impacto balístico, provavelmente pela configuração dos poros e fases presentes nos contornos de grãos [9]. 


\section{CONCLUSÃO}

Da análise das composições investigadas, quanto a dureza, densificação e absorção de energia pelo material cerâmico, verifica-se as fases formadas da interação da alumina com adições de nióbia, sílica e magnésia tem forte influência nessas propriedades.

Para o teor de $8 \%$ de nióbia, a adição de $0,15 \%$ de magnésia e $0,8 \%$ de sílica favorece a formação de uma fase vítrea nos contornos de grãos, como pode ser verificado pela superfície de fratura dessa composição, com aumento nas variáveis investigadas de dureza, densificação e absorção de energia pelo cerâmico, em relação à composição com $8 \%$ de nióbia e $0,8 \%$ de sílica.

Para o teor de $6 \%$ de nióbia, a adição de $0,15 \%$ de magnésia não melhorou a absorção de energia da composição com $0,8 \%$ de sílica, apesar de aumentar a densificação e a dureza, o que provavelmente pode estar relacionado com o fato de não se formar a fase vítrea nos contornos de grãos, e a configuração dos poros não ser favorável à atuação do cerâmico como proteção balística.

\section{REFERÊNCIAS}

1 XAVIER C., COSTA CRC da. Estudo do Comportamento Mecânico de Placas de Alumina sob Impacto Balístico. 28 Congresso Brasileiro de Cerâmica, 30 (175) - Julho 1984.

2 ACCHAR W. Produção de Alumina Sinterizada com Adições de Nióbia. Rio de Janeiro : Instituto Militar de Engenharia, 1985.

3 GOMES, Alaelson Vieira. Comportamento balístico de alumina com adições de nióbia, sílica e magnésia - Dissertação de mestrado. Instituto Militar de Engenharia. Rio de Janeiro. 1999.

4 ASSIS JMK.Estudo comparativo de compósitos alumina-zircônia tetragonal e de cerâmicas de alumina aditivadas com nióbia para aplícações estruturais. Tese de Mestrado - INPE. São José dos Campos. 2007.

5 JAMES B. Practical issues in ceramic armor design. Ceramic Armor Material by Design.2002; 134: 23-31

6 TRINDADE, WILLIAN. 2012. Influência da geometria e da microestrutura no comportamento dinâmico da alumina aditivada com nióbia. Rio de Janeiro : INSTITUTO MILITAR DE ENGENHARIA, 2012

7 GOMES AV. Comportamento balística da alumina com adição de nióbia e variação da geometria do alvo. Tese de doutorado - IME. Rio de Janeiro. 2004.

8 REED JS. Principles of Ceramics Processing. New York: John Wiley \& Sons; 1995.

9 MEYERS MA. Dynamic behavior of materials. Nova York : John Wiley \& Sons; 1994.

10 Norma ABNT NBR 6220 - Material Refratário Denso - Determinação da Massa Específica Aparente, Porosidade Aparente, Absorção e Massa Específica Aparente da Parte Sólida. 1997. 